\title{
Vein of Galen Malformation an Unusual Cause of PPHN in a New Born \\ Venkatesh HA*
}

Consultant Neonatologist, Manipal Hospital, Bangalore, India

*Corresponding author: Venkatesh HA, Consultant Neonatologist, Manipal hospital, Bangalore, India, Tel: 9180 2502 388; E-mail: Venkatveena46@gmail.com Rec date: April 24, 2014, Acc date: April 25, 2014, Pub date: April 27, 2014

Copyright: (C) 2014 Venkatesh HA. This is an open-access article distributed under the terms of the Creative Commons Attribution License, which permits unrestricted use, distribution, and reproduction in any medium, provided the original author and source are credited.

\section{Images in Neonatology}

This male baby was born at 36 weeks of gestation by spontaneous vaginal delivery with antenatal diagnosis of vein of Galen malformation. After delivery, following short bag and mask ventilation, nasotracheal intubation was performed. Baby required high ventilator settings with $\mathrm{FiO}_{2}$ of $100 \%$. Ultrasound cranium showed (Figure 1A) vein of Galen malformation and CT demonstrating the malformation (Figure 1B). Echocardiography done demonstrated evidences of severe pulmonary hypertension (Figure 2A and $2 \mathrm{~B}$ ).
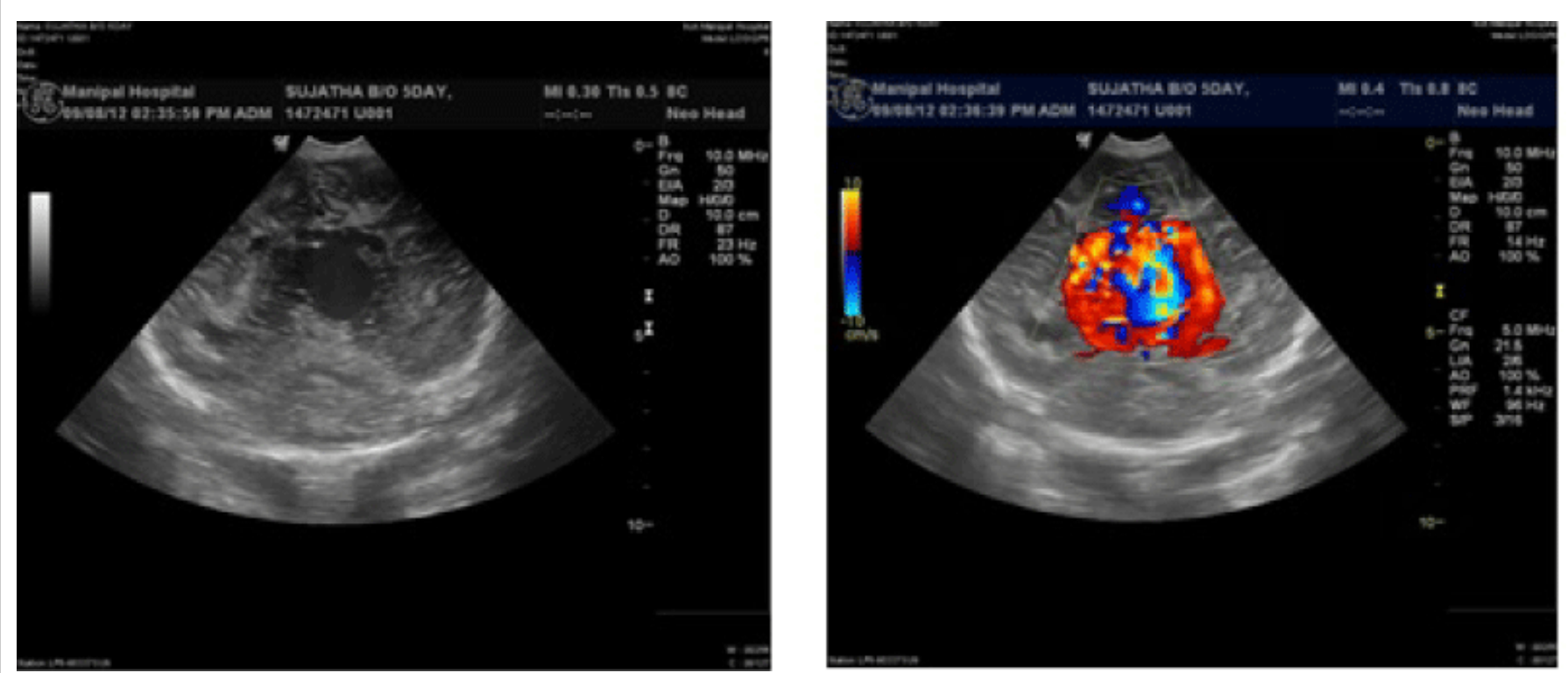

Figure 1A. 2D and Doppler images showing Vein of Galen malformation with feeding vessels 
Citation: Venkatesh HA (2014) Vein of Galen Malformation an Unusual Cause of PPHN in a New Born . J Neonatal Biol 3: 138. doi: $10.4172 / 2167-0897.1000138$

Page 2 of 3
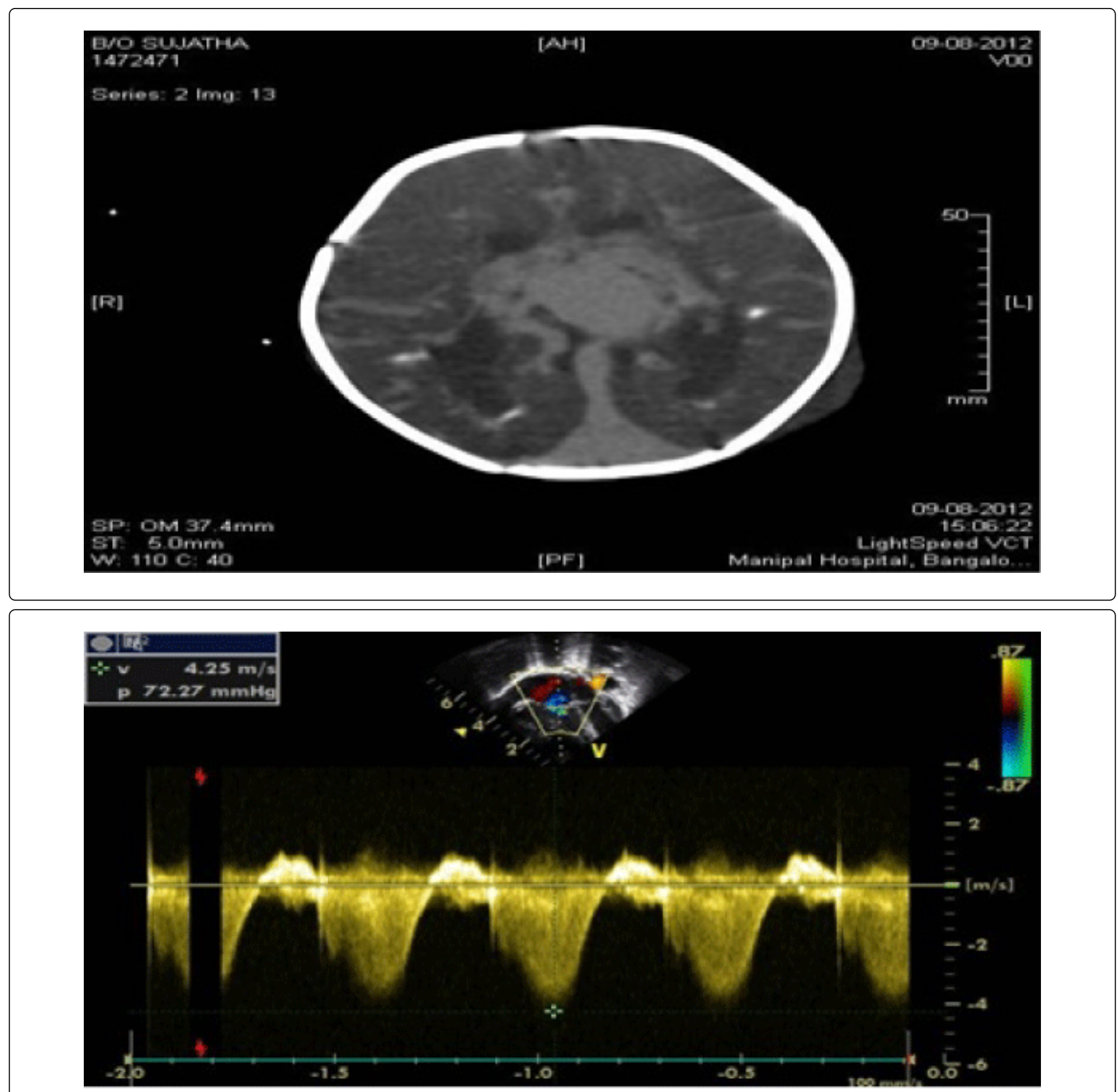

Figure 2A: Continuous wave (CW) Doppler at tricuspid valve showing tricuspid regurgitation and pulmonary pressure of $72.27 \mathrm{mmHg}$ 
Citation: Venkatesh HA (2014) Vein of Galen Malformation an Unusual Cause of PPHN in a New Born . J Neonatal Biol 3: 138. doi: 10.4172/2167-0897.1000138

Page 3 of 3

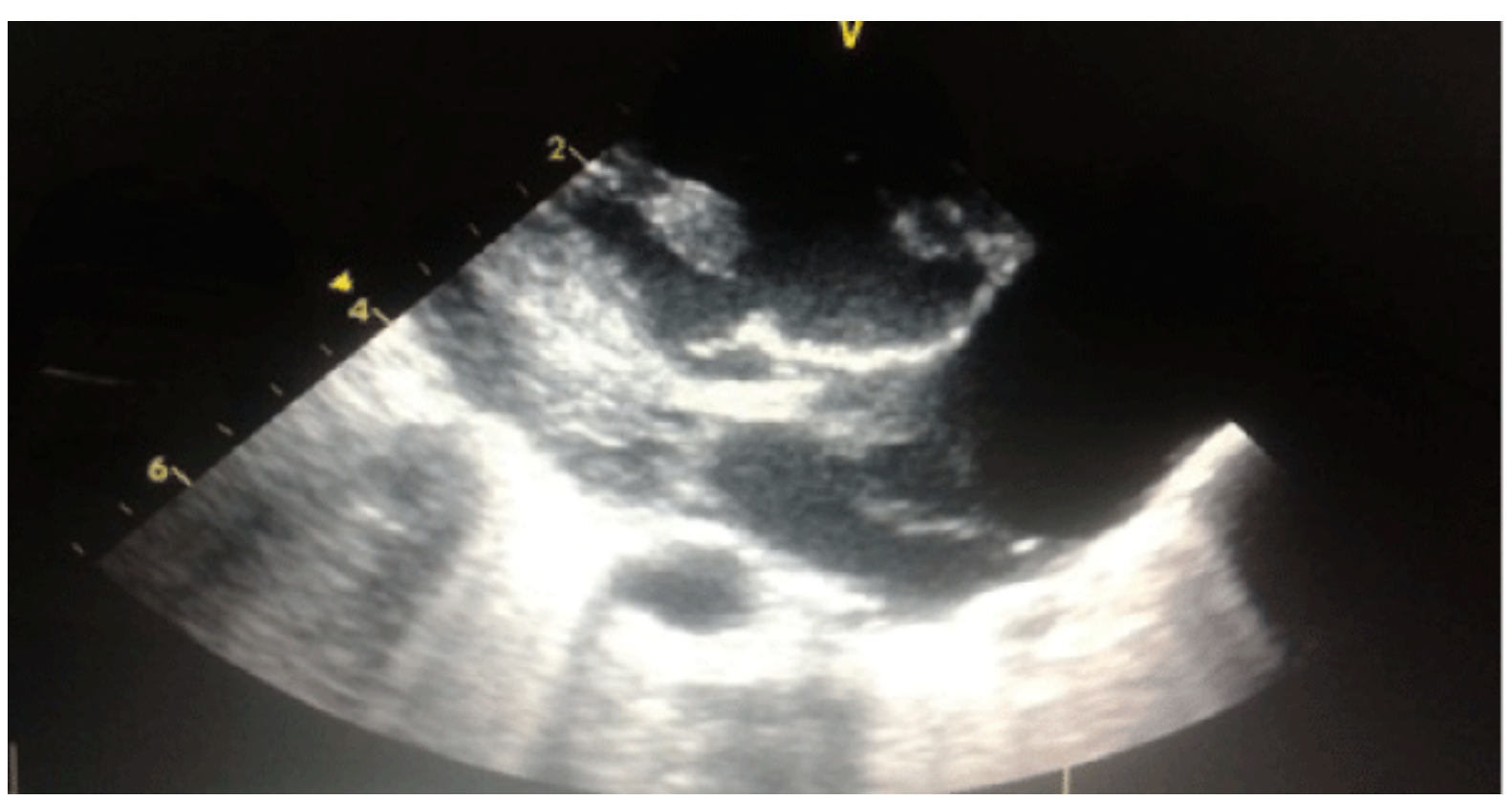

Figure 2B: Parasternal long axis view showing right ventricular hypertrophy.

\section{Discussion}

Association of PPHN with vein of Galen malformation is well established. This information is of utmost importance in any baby with refractory PPHN to have ultrasound brain done. 